\title{
The Strategic DeVElopMent of PHYSIOTHERAPY IN SOUTH AFrICA PAPER 2: MAPPING STRATEGY - CRITICAl CHOICES OVER 30 YeARS
}

\begin{abstract}
This paper demonstrates an unusual approach to trace decision makers' interpretations over time as they attempt to understand environmental events. The paper adopts an evolutionary perspective and methodologically, demonstrates a way of tracing changes in cause maps over time from available documents and statements. Arguments are offered for the usage of such data to infer cognitive processes. The South African Society of Physiotherapy is the subject of study.
\end{abstract}

\section{BOWERBANK $P$, MCSP, MBL, BA (Hons)'}

1 Emeritus Professor, Faculty Health Sciences, University of Cape Town

\section{The author conducted this research as part of a study for a PhD degree.}

"I have been very privileged to be your Chairman at the most exciting point in our Society's history. In April of this year the election took place for the first Professional Board for Physiotherapyit was a very proud moment for us all." Chairman's report SASP council minutes 1973.

The South African Society of Physiotherapy is committed to being a dynamic, united, innovative and professional organisation; effectively representing its members and playing an active role in the formulation and implementation of health care policy in South Africa. PhysioForum Sept 2000.

Why are some organisations able to adjust to changing circumstances while others fail to respond to environmental changes that threaten their long-term viability?

To what extent are professional organisations shaped by their environment, that is, by the network of individuals, groups, agencies and institutions with whom they must interact? Are there organisational characteristics such as strategies, structures, processes which work for one environment or period of time but which may fail in another? Are there linkages across these characteristics which determine organisational success?

\section{PURPOSE}

The purpose of this paper is firstly to reveal a method for conducting longitudinal field research on change in a professional organisation. Specifically the research task is to link the content, context and processes of change and transformation in the South African Physiotherapy profession over 30 years, from $1971-2000$. Secondly the purpose of the research reported here is to gain insight into how interpretations, made by decision makers in the physiotherapy profession, change over time to accommodate unfamiliar concepts and to reconceptualise familiar ones and to link this interpretation process to the timing and content of strategic change.

How do the decision-makers in the physiotherapy profession view their environment? How does this affect the course of action they prescribe for the profession? How do they revise these conceptions? Professional service organisations differ from industrial organisations, they are characterised by a high degree of self-management and collegial control, since only other professionals are held responsible to evaluate their peers (Botha and Orkin, 1993). The physiotherapy profession in South Africa is represented by its professional association, a non-statutory body which relies on voluntary membership from the student and qualified physiotherapists in that country. The professional association plays an important function and role in the development of the profession (Bowerbank, 2000; Richardson, 1999). In order to maintain enduring membership it has to actively pursue the common mutual beneficial goals and interests of its members. Broadly speaking these goals include: to exert influence on state regulators; to promote the collective good of the members; to obtain economic advantage; and to enhance the image of the profession. As such, and as the principal decision making body for the physiotherapy profession in South Africa, the professional association the South African Society of Physiotherapy (SASP) presents the ideal subject for the purpose of the research outlined above.

\section{CONCEPTUAL UNDERPINNINGS}

The strategy literature stresses the need to be concerned with understanding how organisations adapt to their changing

CORRESPONDENCE TO: P Bowerbank No 7, Albion Road Rondebosch 7700

South Africa

Tel: (021) 685-6314

E-mail: pbowerbk@iafrica.com 
environments and the relationship between an organisation's long term success, even survival, and its ability to maintain strategic alliance with its environment (Barr, 1998). The importance of strategy hinges on the assumption that organisations can and do adapt to changes in their environment.

There is an explicit recognition that change is multifaceted involving political, cultural, incremental, environmental, and structural as well as national dimensions (Pettigrew, 1990). Whereas transformation is change, not all change is transformation; transformation is a major change in an organisation involving a break with existing routines and a shift to new kinds of competencies that challenge organisational knowledge, it involves changes in goals, boundaries and activities (Aldrich, 1999).

Research linking cognition to strategy suggests that organisation action is based upon beliefs that decision makers hold regarding how the organisation can best succeed in its current environment (Daft and Weick, 1984). This belief system is developed over time and is based on time and events presenting a useful "map" for understanding organisational action. Aldrich (1999) suggests that transformation only takes place following an event in the environment, the nature of the response to these events is shaped by the interpretation processes which eventually define that particular event.

A contextual analysis of a process such as change draws on phenomena at vertical and horizontal levels of analyses and the interconnections between those levels through time. An example of this is the effect of regulatory context on the features of professional organisation and interest group behaviour over a time period, eg the incremental change in the ethical ruling for medical referral and its effect on professional development, special interest groups, education and economic advantage.

Cognitive processes may represent an important mechanism by which organisations adapt to their environment. Narayanan and Fahey (1990) argue for a cognitive view of strategy formulation by building their arguments on the concept of causal maps. Causal maps allow the mapmaker to focus on action how the respondent explains the current situation in terms of previous events (Huff, 1990). This view of strategic formulation is therefor more explanatory and is complementary to many of the causal assertions prevalent in the strategic management literature. Research on causal attributions is related to studies of interpretation of specific events and relates this to strategic action.

\section{METHODOLOGY}

Interpretation is a cognitive process and a key difficulty in any research that attempts to identify cognitive processes is that they cannot be measured directly (Barr, 1998). Given the researcher's inability to directly measure the construct of interest, the results of cognitive processes such as written archival attributes must be used as indirect reflections of the cognitive processes that generate them. The key considerations in selecting statements for analysis are: (1) Whose statements to analyse? (2) What type of statements is of interest? (3) How to elicit the information?

Much of the literature on interpretation in professional organisations suggests that rather than one individual guiding the actions of the organisation there is a constellation of jointly held, consensual understandings between groups and individuals within the organisation (Gioia and Sims, 1986). However the interpretations of chairmen are also seen to be most closely related to and reflective of changes in strategic action (Norburn and Birley, 1988).

The major task in the research was to extract relevant data from the considerable amount of available information in order to construct revealed causal maps (RCMs). In a longitudinal study interviews become difficult for two reasons: first the organisation chairpersons may not be available or be difficult to access and secondly even when accessible their memories may have dimmed or be faulty.

A method of generating interpretations for longitudinal studies is content analysis of documents written during the period of interest. The assumption made is that the issues discussed by decision-makers in these documents reflect important concerns of that time.

Cause mapping is a form of content analysis that isolates the assertions within a document that deals with causality or categorisation. Assertions can be mapped to gain a larger picture of changing beliefs and both map structure and individual statements can be examined for changes over time ( Barr, Stimpert and Huff, 1992).

\section{CONTEXT AND STUDY PERIOD}

The research therefor focuses on the minutes of the council meetings held by the SASP from the period 1971 - 1999. The view adopted in this research is that the reports by the chairman of the professional association and the decisions, in the form of motions, passed by the national council are most likely to closely relate to strategic action taken by the physiotherapy profession in South Africa. Whilst statements made by chairpersons in their report are concerned with the past, the motions passed at the meetings are concerned with the future. These statements serve as an important forum in which interpretations are articulated and they are a particularily rich source of causal statements about the environment and professional strategic action.

The source of data is taken from the minutes of all the Council meetings held by the SASP between 1971 - 1999 , meetings were held every two years (except for the later 5 years in the 1990s) - 15 meetings in total. Eight different chairmen held office during this period.

\section{REVEALED CAUSAL MAPS}

Causal maps are revealed to the public by decision makers during the process of public discourse - revealed causal maps are assertions of causality which decision makers choose to reveal to the world around them. Since decision makers employ different words their assertions cannot be compared, consequently their "maps" have to be presented in a way which will serve theoretical ends. A graphic scheme for depicting these assertions is presented in Figure 1 and is anchored on strategic management literature. The scheme is based on that of Narayanan and Fahey (1990), it is built up on three blocks or hierarchies - 


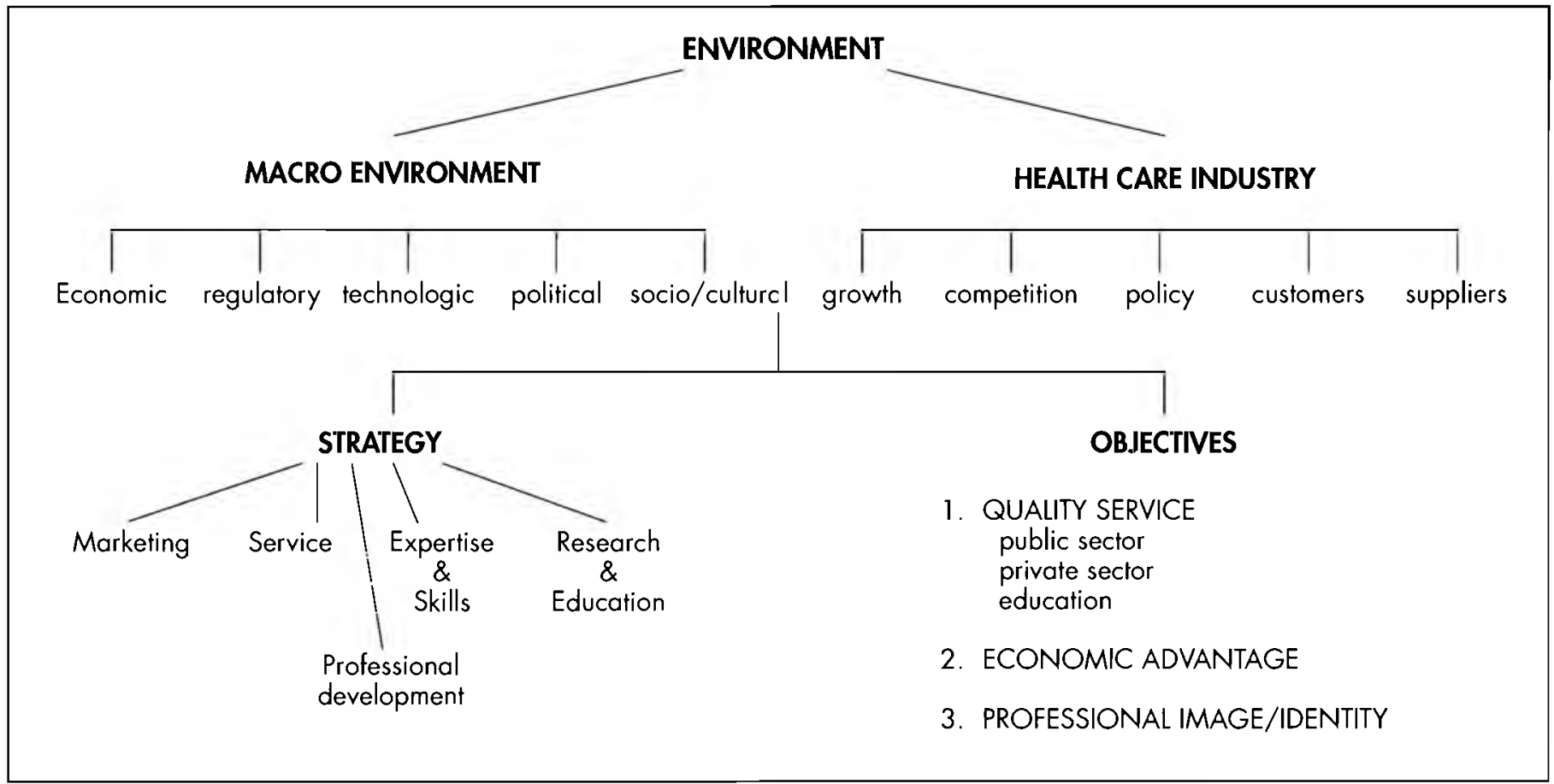

Figure 2: Summary Map of Chairman's Reports

\begin{tabular}{|c|c|c|c|c|}
\hline & $1971-1975$ & $1976-1985$ & $1986-1991$ & $1992-2000$ \\
\hline marketing & 2 & 4 & 0 & 12 \\
\hline service delivery & 6 & 14 & 19 & 13 \\
\hline professional development & 16 & 14 & 8 & 14 \\
\hline expertise & 7 & 2 & 3 & 3 \\
\hline education & 7 & 10 & 5 & 7 \\
\hline growth & 3 & 4 & 5 & 0 \\
\hline competition & 3 & 6 & 0 & 4 \\
\hline policy & 1 & 1 & 5 & 9 \\
\hline customers & 2 & 2 & 7 & 3 \\
\hline suppliers & 2 & 3 & 0 & 4 \\
\hline
\end{tabular}

macro-environment and industry, functional strategy, and objectives. The scheme shown here is adapted for professional health care organisations.

\section{DERIVING REVEALED CAUSAL MAPS Chairman's report}

\section{Stage 1}

The method suggested by (Axelrod, 1976) was adopted for deriving "raw" revealed council maps (RCMs). Only the chairman's reports were used for this part of the research. All the statements in the form of concepts and cause-effect relationships were captured in the language of decision-makers. Only statements that referred to the external environment and strategic development or action were used. Statements referring to internal professional matters were discarded. For each report the statements were aggregated in network charts (Appendix 1).

\section{Stage 2}

The "raw" maps were translated into RCMs using the scheme presented in Figure 1. The concepts were sorted into one of the theoretical categories. Arrows depict the direction of causal linkages.

(Appendix 2)
Stage 3

The RCMs constructed on an annual basis were aggregated over the eras by combining all the causal maps of that era. (Figure 2)

\section{Decisions taken by Council}

\section{Stage 1}

All the motions passed by each council were extracted, only those, which require strategic action connecting with the external environment, were categorised.

\section{Stage 2}

The scheme presented in Figure 1 was used to translate these statements into theoretical concepts. 
Figure 3: Summary map decisions by council

\begin{tabular}{|c|c|c|c|c|}
\hline & $1971-1975$ & $1976-1985$ & $1986-1991$ & $1992-2000$ \\
\hline \multicolumn{5}{|l|}{ FUNCTIONAL STRATEGY } \\
\hline marketing & 2 & 7 & 13 & 3 \\
\hline service delivery & 5 & 11 & 15 & 8 \\
\hline professional development & 6 & 7 & 7 & 4 \\
\hline expertise & 2 & 0 & 2 & 1 \\
\hline education & 1 & 8 & 4 & 5 \\
\hline \multicolumn{5}{|l|}{ OBJECTIVES } \\
\hline quality service/private/public/education & 6 & 12 & 14 & 15 \\
\hline economic advantage/salaries/fees & 6 & 7 & 6 & 0 \\
\hline professional image/identity & 5 & 15 & 21 & 6 \\
\hline
\end{tabular}

Figure 4: Summary External Events and Organisation Adaption

\begin{tabular}{|c|c|}
\hline \multicolumn{2}{|c|}{$1971 \cdot 1975$} \\
\hline EXTERNAL EVENTS & STRATEGIC ACTION \\
\hline * Medical Aid Schemes Act & * Formation private practitioners group \\
\hline $\begin{array}{l}\text { Medical, dental and pharmacy act } \\
\text { * scope of practice } \\
\text { * limited registration }\end{array}$ & Election professional board \\
\hline $\begin{array}{l}\text { Development of Maitland mobilising techniques } \\
\text { - visit by Maitland to SA }\end{array}$ & Formation OMT group \\
\hline * Lack of parity salaries & * Memo and meeting with authorities - \\
\hline * National athletics meeting & * Physio provided round clock service \\
\hline \multicolumn{2}{|c|}{$1977-1983$} \\
\hline $\begin{array}{l}\text { * Remuneration commission established } \\
\text { * Shortage of physios in NW hospitals } \\
\text { * First line practitioner status in Australia for patient referral } \\
\text { * SAMDC agrees to } 4 \text { year degree for all physiotherapy } \\
\text { undergrad training }\end{array}$ & $\begin{array}{l}\text { * PPA forms a tariffs committee } \\
\text { * Training for physiotherapy assistants } \\
\text { * Recommendation to SAMDC for change in SA ethical rule } \\
\text { * Pressure on universities with diploma to comply } \\
\text { * Modern knowledge \& skills to replace old syllabus }\end{array}$ \\
\hline \multicolumn{2}{|c|}{$1985-1991$} \\
\hline $\begin{array}{l}\text { Major technological advances in tertiary health care } \\
\text { *Increase in post graduate courses } \\
\text { * College physio proposed } \\
\text { * QA programmes introduced }\end{array}$ & All training 4 year degree \\
\hline First line practitioner status granted & * Private practice proliferates \\
\hline * Political pressure from world body (WCPT) & * SASP rejects apartheid policies - presents policy to WCPT \\
\hline * Professionalisation in sport & $\begin{array}{l}\text { MSc in sports physio - physio appointed to national } \\
\text { sports teams }\end{array}$ \\
\hline * Increase in professional marketing & * Back week introduced \\
\hline \multicolumn{2}{|c|}{$1993-1999$} \\
\hline $\begin{array}{l}\text { * Change in government \& health care policy and emphasis } \\
\text { on PHC } \\
\text { * Recognition for different levels of health care worker } \\
\text { * Establishment of TRC } \\
\text { * Managed health care in private sector } \\
\text { * Establishment ethics committee } \\
\text { * Accreditation of practices }\end{array}$ & $\begin{array}{l}\text { * Policy statements compiled on all proposed physio services } \\
\text { * Efforts to develop CBR programmes } \\
\text { * SASP makes a submission to TRC } \\
\text { * PPA changes to PhysioFocus \& introduces PhysioNetWorks }\end{array}$ \\
\hline
\end{tabular}


Causal linkages were made between the functional strategy category and objectives for each council meeting (Appendix 3)

\section{Stage 3}

The RCM constructed for each council was aggregated over the eras. (Figure 3)

\section{DATA REPESENTATION AND INTERPRETATION}

The task of presenting the data from the causal maps is not an easy one. In this report $I$ have adopted a descriptive stance and do not address the issues relating to predictive validity of the maps.

\section{Identifying Eros}

This research assumes an evolutionary approach to organisational change, it takes the stance described by Aldrich (1999) that organisational transformations occur within historical and geographical contexts. Transformation often follows an external event, which takes place in the external environment. In this case specific "events" were identified which lead to significant change in the South African Physiotherapy profession. These events divided the period under research into four eras. (All quotes in italics are those of the chairperson at that time).

\section{$1971-1977$}

Three events characterise this era. The amendment to the South African Medical, Dental and Pharmacy act 1971 heralded the election, in 1973, of the first Professional Board of Physiotherapy - a statutory body which greatly increased the autonomy of the physiotherapy profession. As shown at the beginning of this article the chairman described this as "the most exciting point of our society's history". A second event during this period was the first visit to South Africa by Mr Geoff Maitland who was invited to run a course on the mobilising techniques, which bore his name. His visit was described as "an unparalleled success" and was to change much of the way physiotherapists practised. The third event was the prescription, in 1976, of certain magisterial districts (in fact most of the old apartheid era South Africa) whereby only registered physiotherapists could practise in those areas "a fulfillment of a long awaited dream - the culmination of many many years of dogged determination by those who served this society so faithfully".

\section{7 - 1985}

In 1979 at a meeting of the world body (WCPT) the Australian Physiotherapy Association presented the concept of first line practitioner status for physiotherapists. Following this, in 1981, the South African Society of Physiotherapy (SASP) sent a comprehensive memo to the South African Medical and Dental Council (SAMDC) recommending a change in the ethical rule for patient referral "the acceptance will have far reaching implications - a major shift in professional status, responsibility and accountability". This was accepted and promulgated in 1985

Member countries of WCPT mounted increasing political pressure on the SASP because of the apartheid policies held in the country "we are under fire from certain countries regarding acceptable policies in this country - we will have to convince the international body that we as a society do not necessarily subscribe to those views".

\section{5 - 1991}

This era was characterised by increasing pressures from health activists for the recognition of different levels of health worker "there is a need to distribute rehabilitation services throughout the community - the future structure must include the facility for entry into the profession at several levels". This pressure was coupled with declining health budgets in state health and radical cuts in public health expenditure "the fragmentation of the health service has made availability of health care to all people even more difficult".

\section{1 - 1999}

The single most spectacular event, which took place in this era, was the release from prison of Nelson Mandela and the subsequent change in government and political power "never before has council met at such an auspicious time". Health care policy changed from support for curative tertiary care to that of preventative primary health care (PHC) "perceptions of how the desired health care of the future is to be, vary greatly". The private sector health care moved from a fee for service policy to that of managed health care "we attended a negotiating forum on managed health care - the minefield in privatised health".

\section{DISCUSSION}

Figure 4 summarises the events which took place in the environment, and the resultant changes in the physiotherapy profession. Significant actions took place due to the change in legislation firstly, the formation of the professional board for physiotherapy and secondly, the eventual promulgation of the ethical rules allowing physiotherapists the freedom to practice without a patient referral from a medical practitioner.

Selection of this change in legislation, as one of the focal events, led to the period of interest for this study being 1971 - 1999. Starting the time just prior to the change in legislation provided a baseline for identifying change in interpretation and strategic action.

Porter (1985) describes the 1970s as one of competition - competition amongst occupations - we are separate we must compete. All professional organisations were competing and making demands on money, prestige and power markets. Competition was shaped by economic supply and demand and resulted in:

i) monopoly of tasks and market,

ii) very strict professional entrance requirements; and

iii) shifts in consumer needs.

In order to maintain the position gained in the 1970s several actions had to take place in the 1980 - the competence of the entrants to the profession had to be raised; quality controls were imposed over members work; mechanisms had to be developed for improving professional skills and techniques; and marketing strategies had to be developed. These actions became a source of social change within the physiotherapy profession and developed the foundation for true professionalism - it lead to:

i) new privileges eg PPA negotiated their own tariffs,

ii) graduate education; and 


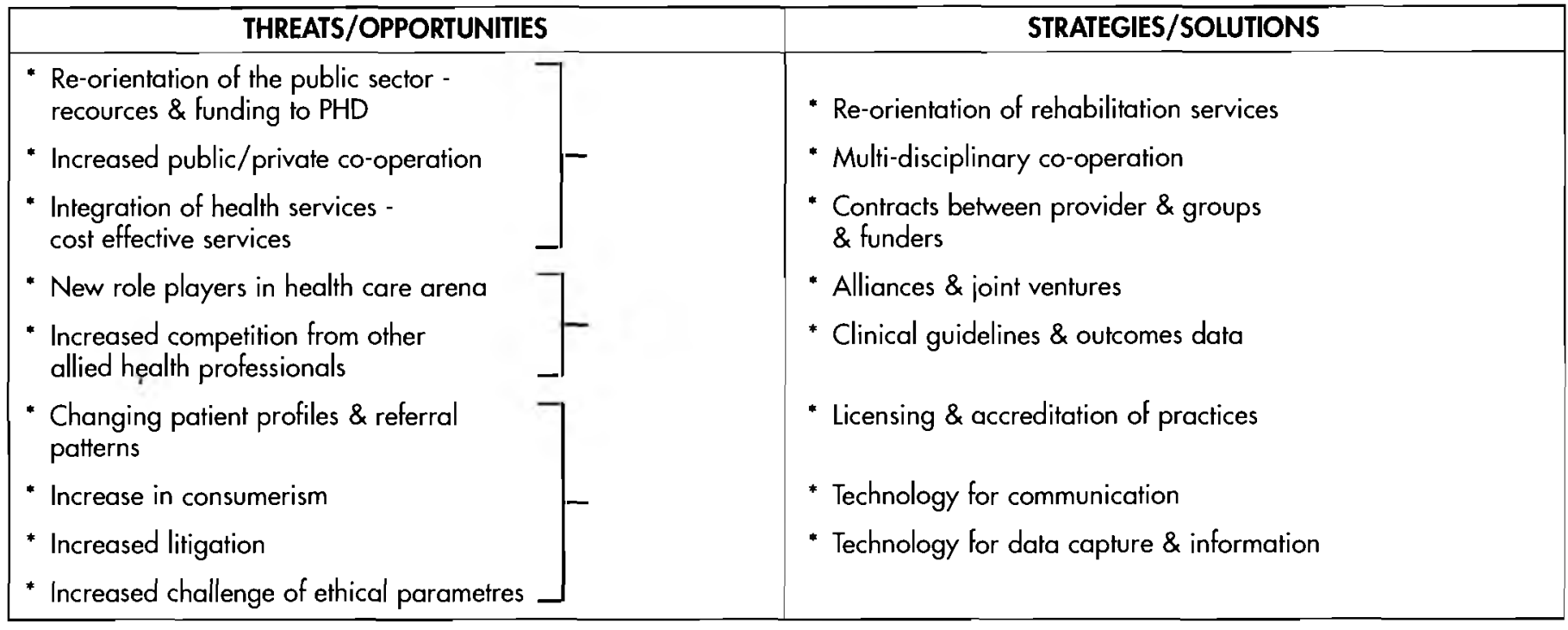

iii) it directed legislation to protect the profession eg who may or not register.

Perusal of Figures 2 and 3 shows how the interpretation by chairman of these eras is focused on service delivery and professional development and the decisions taken by the council are directed at achieving quality service and improving the professional image.

The 1990s saw a complete turn around - competition, usually a powerful force for both quality enhancement and cost reduction appears to be driving costs through the ceiling (Teisburg and Porter, 1994). This resulted in the skewed development of high tech, curative services being halted; closure of hospitals and services in the public sector; emphasis on primary health care and a move towards managed health care in the public sector. Physiotherapists themselves were deeply affected by these dramatic changes and a flurry of policy statements and a redirecting of service strategies resulted.

\section{IMPI.ICATIONS}

Institutional constituents, including the state, professions and interest groups impose a variety of laws, regulators and expectations on professional bodies.

The maps (Figures 2 and 3) show that the majority of stimulus/cause for organisational change came from the macro environment and most particularily the regulatory and financial context. This is not surprising, institutional theorists have emphasised the survival value of conformity with the institutional environment and the value of adhering to external rules and norms (Oliver, 1990).

Organisations will expect to acquiesce more readily to pressures that do not constrain substantive organisational decisions. However, in 1989, following the considerable pressure from the world body (WCPT) which was threatening expulsion of South Africa from its membership, the SASP took unprecedented steps to defy and challenge the apartheid policy of the government issuing a strongly worded policy document. The likelihood of resistance to institutional pressure is predictable if the organisation is dependent on the constituent who is exerting the pressure. In this case the SASP would have suffered considerably if it were expelled from the world body. A few years later the SASP was able to make a virtue of its insurrection by submitting a document to the TRC acknowledging its faults and omissions of previous years.

In September 2000 the SASP published a new proposed vision and the realities facing the physiotherapy profession in South Africa (FORUM September 2000). I printed the vision at the beginning of this article. I have reorganised the realities into threats/ opportunities and solutions/strategies Figure 5. The threats/opportunities have been categorised into a suitable variable according to Figure 1.

You will notice that they fall into supplier, competition, consumer and policy contexts - none of these variables has figured to any great degree over the past 30 years. Likewise the solutions are all relatively new concepts. Perhaps the physiotherapy profession is on the threshold of a new transformation.

A professional organisation's survival is enhanced if it conforms to social norms of acceptable behaviour, these self serving advantages result in a variety of rewards for example, increased prestige, stability, legitimacy, social support, internal and external support, access to resources, attraction of personnel, acceptance to other professions (Oliver, 1990).

The research described in this article has shown some of the interpretations and decisions made by the physiotherapy profession in South Africa over the past 30 years. Many of these decisions have resulted in action, which have been well rewarded by society as described above.

Though the focus of this research was on identifying specific events and patterns of interpretation across the physiotherapy profession several interesting results suggest that it is not just the interpretation of isolated events that are important to strategic change but also linkages across events. The efforts over the years to have physiotherapy assistants officially recognised and the concept of physiotherapy students doing an internship-year after qualifying were all thwarted until new policies were adopted by government introducing mandatory continuing education and the concept of lifelong learning and seamless 
education. The implications being that successful outcomes are linked to changes in the environment and that key activities change over time as they adapt to the environment.

\section{FURTHER RESEARCH}

This research has several implications for further research. The relationship between the health industry and physiotherapy organisational context and the development of interpretations relating to strategic adaptations remain to be identified. Secondly the relationship between industry and organisational context of the special interests groups of the SASP requires further investigation.

\section{ACKNOWLEDGMENTS}

The author is indebted to Professor Frank Horwitz of the Graduate School of Business, University of Cape Town for all his support during this research and to the administrative staff at SASP headquarters who allowed me to sift through all their archives.

\section{REFERENCES}

Aldrich H E 1999 Organisations Evolving, Sage publications, London

Axelrod R 1976 Structure of Decision, Princeton University Press, Princeton, New Jersey

Barr P S 1998 Adapting to Unfamiliar Environmental Events: A Look at the Evolution of Interpretation and its Role in Strategic Change. Organisational Science 9(6): $644-669$

Barr P S, Stimpert J L, Huff A S 1992 Cognitive Change, Strategic Action and Organisational Renewal. Strategic Management Journal 13:15 - 36

Botha F, Orkin M 1993 Strategies of South African Professional Firms. South African Journal of Business Managemen 24(4): $109-116$

Bowerbank P 2000 The Strategic Development of Physiotherapy in South Africa: Some Theoretical Concepts which relate to Organisational Change. South African Journal of Physiotherapy 56(3): $4-7$

Daft R, Weick K 1984 Towards a Model of Organisations as Interpretive systems. Academy of Management review 9: 284 - 295
Gioia D, Sims H 1986 Social Cognition in Organisations. In: The Thinking Organisation, Sims H and Gioia D (editors). Jossey Bass San Fransisco

Huff S E 1990 Mapping Strategic Thought John Wiley, New York

Narayan V K, Fahey L 1990 Evolution of Revealed Causal Maps during decline. In: Mapping Stregic Thought. Huff S E (editor). John Wiley, New York

Norburn D, Birley S 1988 Top Management Team. Strategic Management Journal: 225 - 237

Oliver C 1990 Determinants of Interorganisational Relationships. Academy management Review 15(2): 241 - 265

Pettigrew A 1990 Longitudinal Field Research on Change. Organisational Science 1(3): $267-292$

Porter M E 1985 Competitive Advantage, Free press, London

Richardson B 1999 Professional Development. Physiotherapy 85(9): 467 - 473

Teisburg E O, Porter M E, Brown G B 1994 Making Competition in Health Care Work. Harvard Business Review, July/Augusı

\section{Appendix 1: An Example of Raw Revealed Causal Map}

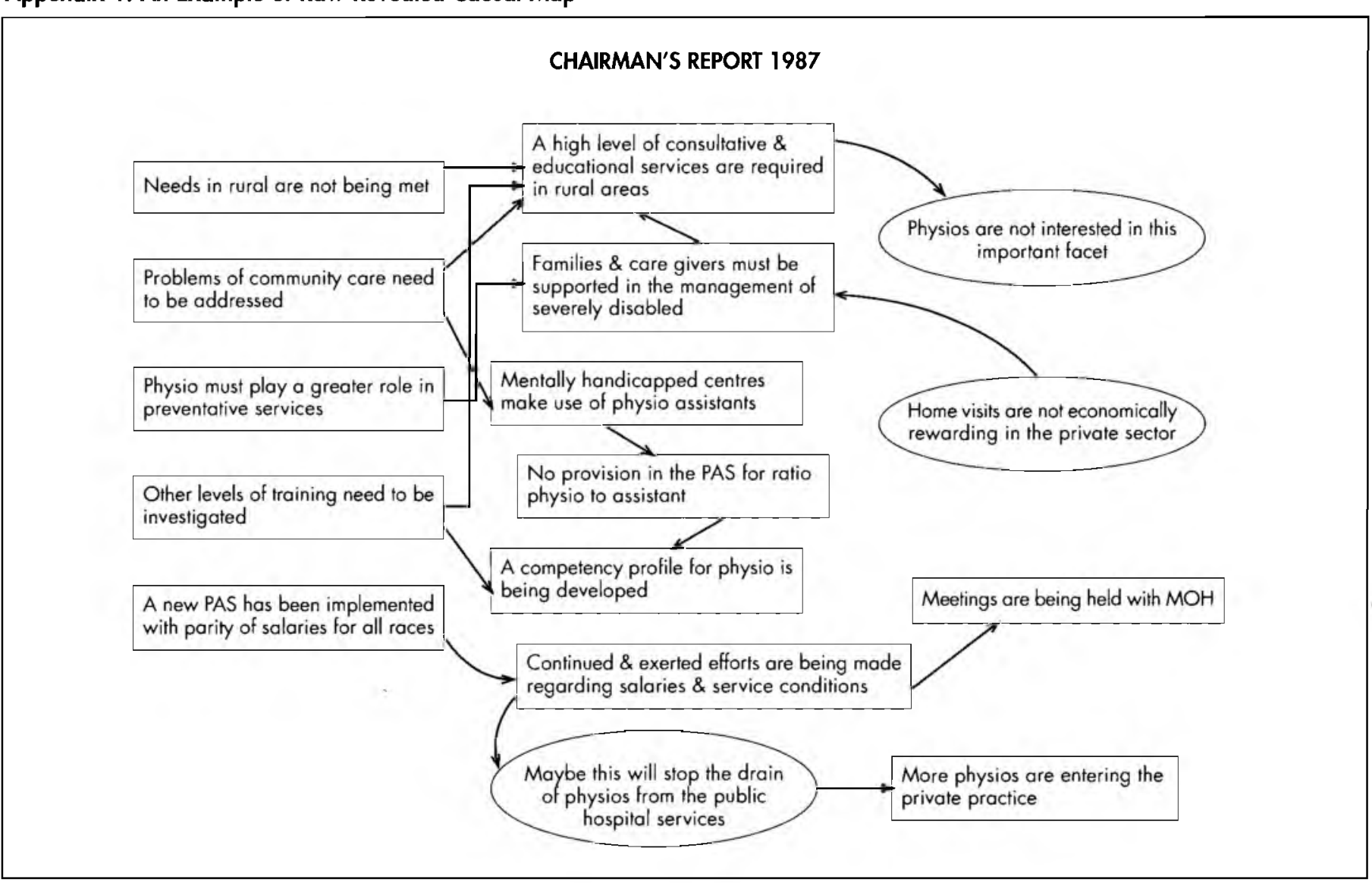




\section{Functional strategy}

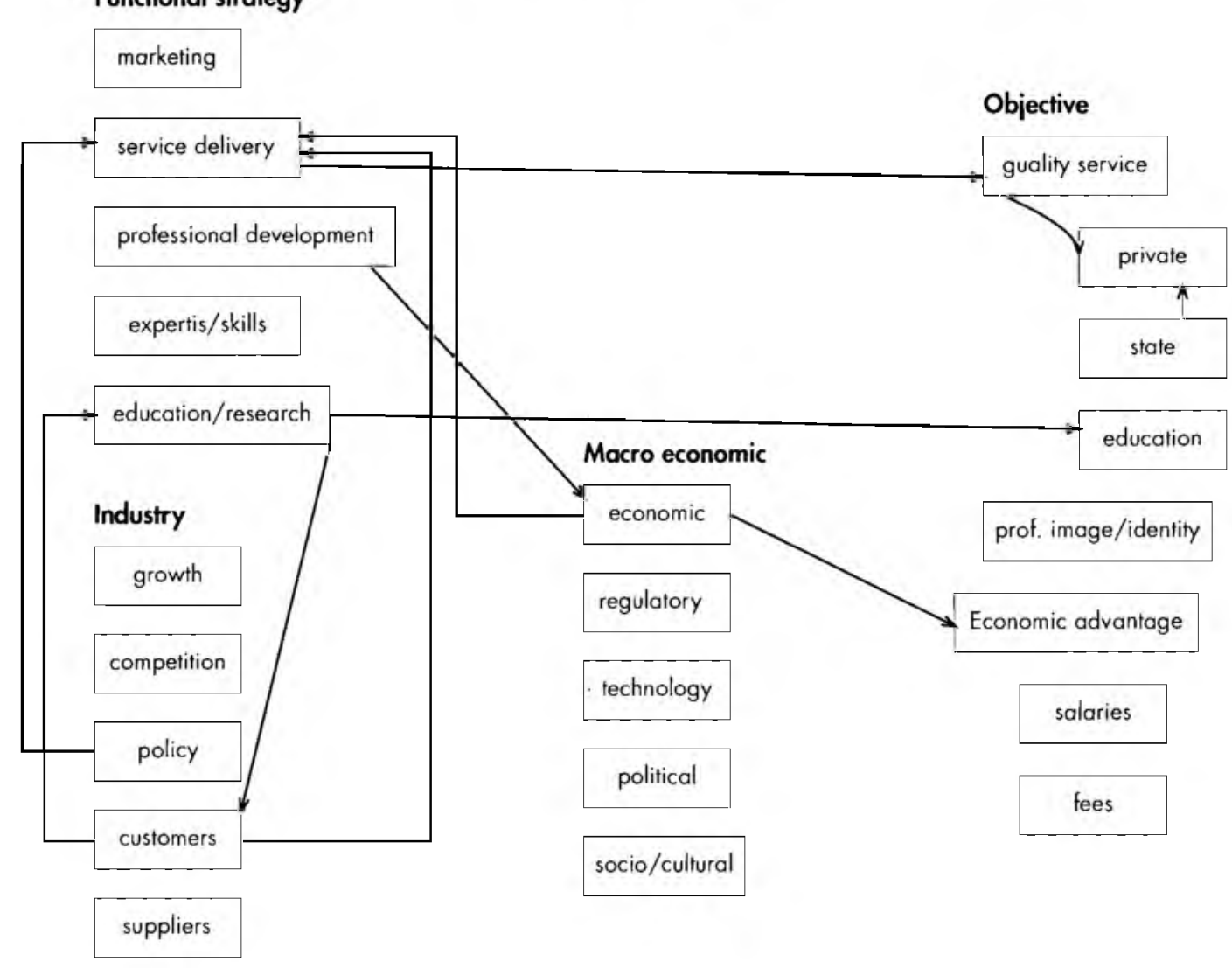

Appendix 3: Constructed Causal Map

\begin{tabular}{|c|c|c|}
\hline & REQUIRED STRATEGY & OBJECTIVE \\
\hline DECISIONS 1987 & & \\
\hline $\begin{array}{l}\text { That the society investigate the possibility of obtaining demographic data } \\
\text { form all PTs annually when they pay their registration fees to SAMDC }\end{array}$ & PD & PROF \\
\hline $\begin{array}{l}\text { Not to undertake the treatment of any patient ... except in an } \\
\text { emergency or in close collaboration with a registered medical...... }\end{array}$ & SD & SERV \\
\hline $\begin{array}{l}\text { A member may enter into association with a registered member of } \\
\text { another supplementary health services profession with the approval } \\
\text { of the Prof board }\end{array}$ & SD & SERV \\
\hline $\begin{array}{l}\text { That the society investigates the respective roles of the university lecturer } \\
\& \text { the hospital PT in the clinical instruction of the PT student }\end{array}$ & $\mathrm{ED}$ & SERV \\
\hline $\begin{array}{l}\text { That the SASP makes representation to Provincial and state authorities } \\
\text { to discontinue the use of the term paramedical when referring collectively } \\
\text { to such professions as PT, OT }\end{array}$ & $\mathrm{PD}$ & PROF I \\
\hline $\begin{array}{l}\text { That the SASP write to the universities to stress the need for higher } \\
\text { degrees for registration in maip therapy }\end{array}$ & $\mathrm{ED}$ & SERV ED \\
\hline $\begin{array}{l}\text { That NEC request the Prof Board to investigate means of ensuring that PTs } \\
\text { are not allowed to open solus practice without one years clinical practice } \\
\text { in an approved institution }\end{array}$ & $\mathrm{SD}$ & SERV \\
\hline
\end{tabular}

